\title{
Educación en derechos humanos: Estrategia pedagógica-didáctica centrada en la controversia ${ }^{1}$
}

\author{
Human Rights Education: A Pedagogical and Didactic (Teaching) Strategy Focused in a \\ Controversial Perspective
}

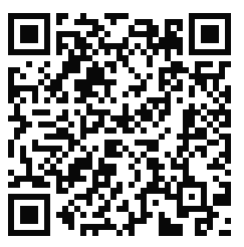

\author{
Abraham Magendzo-Kolstrein ${ }^{2}$ \\ Universidad Academia de Humanismo Cristiano \\ Santiago, Chile \\ Magendzoabraham14@gmail.com \\ María Isabel Toledo-Jofré3 \\ Universidad Diego Portales \\ Santiago, Chile \\ maria.toledo@udp.cl
}

Recibido 30 de octubre de 2013 • Corregido 27 de julio de 2015 • Aceptado 31 de julio de 2015

\footnotetext{
1 Este artículo es producto del Proyecto FONDECYT № 1120742, “Estudio sobre la enseñanza de los 'temas controversiales' en el curso de Historia, Geografía y Ciencias Sociales, durante el primer ciclo de enseñanza media. Análisis de las estrategias de afrontamiento: Adoctrinamiento versus neutralidad".

2 Profesor de Estado en Educación, Master en Educación e Historia Universidad Hebrea Jerusalén-Israel.; Doctor en Educación Universidad de California-Los Ángeles-California USA. (UCLA); Post-doctorado en Curriculum, Instituto de Educación Universidad de Londres Inglaterra. Director académico del Doctorado en Educación y coordinador Cátedra UNESCO en Educación en Derechos Humanos, Universidad Academia de Humanismo Cristiano; investigador Programa Interdisciplinario de Educación en Educación (PIIE). Áreas de interés académico: curriculum y pedagogía; educación en derechos humanos; educación ciudadana, convivencia escolar, resolución de conflictos; bullying, violencia escolar, memoria y educación. Publicaciones varias: ver Google Abraham Magendzo K.

${ }^{3}$ Antropóloga y Licenciada en Antropología, Universidad de Chile, Chile; Doctora en Ciencias de la Educación por la Universidad Católica de Lovaina, Bélgica. Profesora titular de la Escuela de Psicología, Facultad de Psicología, Universidad Diego Portales. Docente de pre-grado y pos-grado en psicología. Profesora y asesora en metodologías hermenéuticas, especialmente, enfoque biográfico y etnografías. Investigadora en dos líneas del conocimiento: memoria colectiva/enseñanza de la historia en la escuela y violencia/intimidación en la escuela.
} 
doi: http://dx.doi.org/10.15359/ree.19-3.2

URL: http://www.una.ac.cr/educare

CORREO: educare@una.cr

Resumen. El propósito de este artículo, que puede ser concebido como un ensayo, es presentar una estrategia pedagógica-didáctica para la educación en derechos humanos centrada en la controversia. Para fundamentarla, se exponen los desarrollos y obstáculos que ha enfrentado la educación en derechos humanos en América Latina. De ahí, se evidencia que ella ha negado el conflicto y se explica la necesidad de su inclusión bajo la noción de 'tema controversial'. Luego, se muestra la existencia de conflictos en la interpretación, vulneración o aplicación de los derechos humanos. Se exponen las principales tensiones que los cruzan. En función de lo anterior, se fundamenta la necesidad de la existencia de una enseñanza de los derechos humanos centrada en el conflicto y se describen elementos centrales de su estrategia pedagógica, para finalizar refiriéndose a su estrategia didáctica y al rol que debe asumir el profesorado para enseñar derechos humanos incorporando el conflicto.

Palabras claves. Educación en derechos humanos, pedagogía crítica, temas controversiales.

Abstract. The purpose of this article, which can be envision as an essay, is to present a pedagogicaldidactic strategy for human rights education focusing on the controversy. Advancements and setbacks faced by human rights education in Latin America are exposed in order to support this strategy. Therefore, it indicates that education has denied the conflict and explains the need for its inclusion under the idea of 'controversial issue'. Additionally, the existence of conflicts in the interpretation, violation and/or respect for human rights is pointed out. The principal tensions that cross human rights are displayed. Based on the above, the need to support the existence of a human rights education focusing on the conflict and central components of its teaching strategy are described, and it ends by referring to its didactic approach and the role which should be assumed by faculty when teaching human rights including the conflict.

Keywords. Human rights education, critical pedagogy, controversial issues.

El propósito de este artículo es presentar una estrategia pedagógica-didáctica para la educación en derechos humanos centrada en la controversia. Esta propuesta se funda en los postulados de la pedagogía crítica. Por ello, pretende reforzar el cometido ético-político de la educación en derechos humanos. Al tiempo que, se propone vincular al estudiantado con los grandes problemas y tensiones que enfrentan las sociedades en el presente.

Cabe destacar que analizar las controversias que emergen en el campo de los derechos humanos permite al estudiantado desarrollar competencias cognitivas, afectivas y sociales necesarias para la formación de una ciudadanía crítica y defensora de los derechos humanos, capaz de participar activamente en una sociedad democrática. Por tanto, habilita al estudiantado para analizar críticamente el respeto, la aplicación y la violación de los derechos humanos en situaciones en las cuales está implicado por proximidad territorial, social o afectiva. Simultáneamente, permite el reconocimiento de puntos de vista diferentes a los propios, desarrollar argumentaciones y tomar posición ante las situaciones analizadas. 
doi: http://dx.doi.org/10.15359/ree.19-3.2

URL: http://www.una.ac.cr/educare

CORREO: educare@una.cr

\section{Desarrollos y obstáculos de la educación en derechos humanos en América Latina}

La educación en derechos humanos en América Latina comenzó a desarrollarse en la década de 1980, desde los movimientos sociales y con estos: movimiento de educación popular, movimientos por la paz, movimientos feministas, movimientos de trabajadores, movimientos de derechos de las minorías, etc. Tomó como base el pensamiento de Paulo Freire, quien trabajó con convicción de que es a través del diálogo como las personas aprenden y toman conciencia de que son sujetos de derecho, al tiempo que inician su propio proceso de 'liberación'. Desde esta perspectiva, la educación en derechos humanos se posicionó como una educación ético-política.

Desde esa época, la educación en derechos humanos se ha desarrollado en un contexto político, económico, social y cultural que la condiciona, la proyecta y en ocasiones la obstaculiza. Esto, porque en muchas ocasiones la temática de los derechos humanos cobra vigencia en el espacio público cuando se enfrentan situaciones traumáticas, como son: dictaduras, violencia institucionalizada, impunidad, corrupción, falta de ética en la acción pública y privada, la situación de pobreza en la que se encuentran la mayoría de la población de América Latina, etc.

Pero, a pesar de los obstáculos encontrados, la educación en derechos humanos, en las sociedades actuales, se ha transitado paulatinamente hacia el reconocimiento de la dignidad humana. $Y$, en este devenir, se ha hecho evidente que, a las nuevas generaciones hay que educarlas en relación con el respeto de los derechos humanos. Por ello, la educación en derechos humanos se ha incorporado progresivamente a los currículos estaduales o nacionales de la educación formal en casi la totalidad de los países de América Latina y se la ha reforzado en la educación no-formal (educación popular, educación de adultos). Además, se han institucionalizado equipos y líneas de investigación; publicado libros y artículos científicos; producido material didáctico; realizado congresos, simposios y talleres dedicados capacitar a especialistas y a profesores. En distintos países se han organizado redes de especialistas y profesionales en educación: red brasilera, red peruana, red chilena, red uruguaya, por nombrar algunas. Se han creado institutos latinoamericanos de educadores en derechos humanos, a saber: Red del CEAAL, Red Universitaria de Derechos Humanos en América Latina, Instituto Interamericano de Derechos Humanos. También se ha formado y capacitado a especialistas y docentes en todos los países de la región (Sacavino, 2012).

Por sobre todo, como resultado de la las acciones realizadas, se han consolidado algunos marcos teóricos referenciales y se han afianzado algunas ideas-fuerza que, actualmente, orientan el quehacer de la educación en derechos humanos. Entre estas ideas-fuerza cabe destacar las siguientes: 
doi: http://dx.doi.org/10.15359/ree.19-3.2

URL: http://www.una.ac.cr/educare

CORREO: educare@una.cr

- es una educación contextualizada

- es una educación constructora de democracia

- tiene un carácter político-transformador

- es integral y holística

- tiene una sentido ético-político

- es constructora de paz

- se orienta a la formación de sujetos de derecho

- no está exenta de tensiones, conflictos y controversias (Magendzo, 2009).

Resultado de su desarrollo y resolución de los obstáculos enfrentados, actualmente en América Latina, la educación en derechos humanos, es parte integral de las políticas públicas de calidad de la educación. Es reconocida en las escuelas y gradualmente ha ido incorporándose en las instituciones formadoras de maestros y maestras. Además, la educación en derechos humanos se ha diversificado, de suerte que son múltiples las instituciones de la sociedad civil y organizaciones no gubernamentales (ONG) que han asumido tareas de difundirla y desarrollado programas educacionales en ámbitos específicos como son: educación en género, educación ambiental, educación ciudadana, educación multicultural, educación en valores, educación para la paz, educación para la convivencia, la tolerancia y no la discriminación, etc.

Sin embargo, a pesar del reconocimiento logrado y de su desarrollo teórico y pedagógicodidáctico, la educación en derechos humanos enfrenta tensiones y dilemas aún no resueltos.

En primer lugar, existe una tensión respecto a la estrategia de inserción de los derechos humanos en el currículo: para algunos, debiera incorporarse como una asignatura más de la malla curricular, asignándole un número de horas programáticas. De esta forma, los derechos humanos adquieren estatus y poder al concebírselos como una materia tan válida como lo es la matemática, el lenguaje, las ciencias, la historia y las ciencias sociales, las artes, etc. Pero también, hay quienes sostienen que los derechos humanos debieran ser abordados transversalmente en el currículo, incorporándolos en todas las asignaturas. El argumento que avala esta postura es que los derechos humanos están vinculados y pueden enseñarse, de una u otra manera, en todas las disciplinas que aborda el currículo. Por ejemplo, el lenguaje que entrega las habilidades comunicativas permite argumentar la defensa de los derechos propios y de las demás personas; la matemática vinculándola con temas sociales; las ciencias con los derechos reproductivos y ambientales; la historia y las ciencias sociales con los derechos políticos, económicos, sociales y culturales; las artes con el derecho a la libre expresión, etc. De esta forma, son todas las asignaturas responsables de la adquisición de conocimientos, habilidades y actitudes vinculadas con los derechos humanos. 
doi: http://dx.doi.org/10.15359/ree.19-3.2

URL: http://www.una.ac.cr/educare

CORREO: educare@una.cr

La segunda tensión refiere a la contradicción existente entre un discurso ciudadano y de quienes velan por la defensa de los derechos humanos, que apunta a la formación de estudiantes respetuosos y defensores de los derechos humanos y alertas frente a su violación, y la realidad social, cultural, económica y política que, cotidianamente, conculca los derechos de las personas. Esta contradicción se reproduce en el ámbito escolar, puesto que, el currículo manifiesto-oficial expone un discurso articulado y democrático de conocimientos, habilidades y actitudes en torno a los derechos humanos y una cultura escolar autoritaria, un reglamento disciplinario inconsulto y relaciones interpersonales entre docentes y estudiantes, en ocasiones, intolerantes y discriminadoras, lo contradicen.

Una tercera tensión refiere a la existencia de una polisemia de lenguajes y programas vinculados a los derechos humanos: las instituciones educacionales han sido objeto de una multiplicidad de programas educativos de educación cívica, educación ética, educación sexual, educación para el desarrollo sustentable, educación para la convivencia y la no violencia, educación para la paz, etc. Pero sucede que, si bien todos estos programas se orientan a la formación de estudiantes que contribuyan a la construcción de una sociedad más igualitaria, justa y humana -y en este sentido a la vigencia de los derechos humanos-, su convergencia no es explicitada, esclarecida ni explicada. Cada programa aparece como un compartimiento estanco, desligado de los otros, generando confusiones y dificultades en su enseñanza e incluso el rechazo a tal diversidad de acciones (Magendzo, 2000).

Una tensión adicional remite al hecho de que, en general, las escuelas de América Latina se han centrado preferentemente en el desarrollo de competencias cognitivas, en el aprendizaje memorístico y en contenidos desvinculados de los problemas económicos, socio-culturales y políticos contingentes y de los intereses de sus estudiantes. Mientras que la educación en derechos humanos, por definición, es problematizadora, contextualizada, política, vinculada con las emociones y con la vida presente y futura del estudiantado. Por ello, en ocasiones, la educación en derechos humanos aparece como disruptiva, desafiante e incluso provocadora y conflictiva.

La existencia de estas tensiones manda a continuar la reflexión para que la educación en derechos humanos se mantenga al servicio del proyecto histórico que permita erradicar las injusticias, las discriminaciones, las inequidades y la falta de reconocimiento de la diversidad política, social y cultural que caracteriza a las sociedades actuales.

\section{Negación del conflicto}

Como se evidencian en las tensiones expuestas, el conflicto está siempre presente en la educación en derechos humanos. Además, incorporar el conflicto en la educación en derechos humanos es un imperativo ético-político ineludible. Esto, porque el conflicto es parte inherente a los derechos humanos, ya que estos se han construido como resultado de disputas entre grupos y pueblos. Y es precisamente esta historia saturada de intensas e incesantes luchas y conflictos la que obliga a la vigilancia de su cumplimiento. 
doi: http://dx.doi.org/10.15359/ree.19-3.2

URL: http://www.una.ac.cr/educare

CORREO: educare@una.cr

No se debe olvidar que la Declaración Universal de los Derechos Humanos (Naciones Unidas, 1948) surgió después de la Segunda Guerra Mundial, cuando la comunidad internacional tomó conciencia de las múltiples e inhumanas violaciones a los derechos humanos que se habían cometido. Además, por su propia naturaleza, los derechos humanos siempre se plantean en la disyuntiva existente entre su vigencia y su atropello, entre el discurso que induce a su cumplimiento y un contexto que los infringe (Magendzo y Donoso, 1992).

Sin embargo, no solo en el ámbito de los derechos humanos se ha negado el conflicto. La escuela -frecuentemente- también presenta la realidad social como un sistema de cooperación donde sus partes constituyentes se vinculan en una relación funcional y cada elemento aporta al mantenimiento de la continuidad de la sociedad. Por tanto, el conflicto se presenta como antitético al adecuado funcionamiento social (Apple, 1986). También sucede que la escuela presenta el conocimiento científico como un saber consensuado, negando todas las tensiones y conflictos que permiten generar los nuevos saberes (Apple, 1986).

De lo anterior se hace evidente que no es posible trabajar en educación en derechos humanos sin incorporar el conflicto.

\section{Inclusión del conflicto}

El conflicto en educación se introduce al currículo con el concepto de 'tema controversial'. Estos son, como han sido definidos en Toledo, Magendzo, Gutiérrez e Iglesias (en prensa) y Toledo, Magendzo, Gutiérrez, Iglesias y López-Facal (en prensa) situaciones, temas, problemáticas sociales sobre los cuales los grupos sociales no han logrado construir un consenso (Crick, 1998 en Levinson, 2006). Se trata de temas que, a nivel social, producen conflictos (Vashist, 1993, en Asimeng-Boahene, 2007). Estos tópicos o situaciones dividen la sociedad, porque los diferentes grupos que la componen han entregado explicaciones o soluciones diferentes que son irreconciliables entre sí (Crick, 1998; Oultdon, Day, Dillon y Grace, 2004 y Wales y Clarke, 2005, en Levinson, 2006; Stradling, 1985, en Oultdon et al., 2004). Esta diferencia o diversidad de interpretaciones o explicaciones se funda en creencias y valores que portan los diferentes grupos (Stradling, 1984, en Harwood y Hahn, 1990).

En el ámbito de los derechos humanos también existen conflictos en su interpretación, vulneración oaplicación. En muchas ocasiones, las situaciones vinculadas alos derechos humanos se tornan conflictivas porque están en juego propuestas distintas sobre su jerarquización.

Además, como indica Castillo (2005, pp. 102-104):

Actualmente es bastante común, tanto en la doctrina (Rodríguez, 1988; Peces-Barba, 1999; Prieto Sanchís, 1992.; Rüfner, 1976; Schlink, 1976; Bethge, 1977; Schneider, 1979; Hess, 
doi: http://dx.doi.org/10.15359/ree.19-3.2

URL: http://www.una.ac.cr/educare

CORREO: educare@una.cr

2000) como en la jurisprudencia constitucional, que se hable de "conflicto" de derechos fundamentales. Según una visión conflictivista de los derechos fundamentales éstos son realidades que eventualmente pueden entrar en oposición entre sí. Esto es así porque se tiene el convencimiento de que:

Al ejercer un derecho fundamental, éste se puede encontrar enfrente, en postura disconforme a la de ese ejercicio con el titular de otro derecho fundamental que pretende igualmente ejercerlo. En caso de conflicto o de antinomia subjetiva, si se permite la paradoja, quien debe ceder y quien debe continuar cómo se construye ese límite al derecho fundamental, son preguntas claves para una teoría de los derechos fundamentales. (Peces-Barba, 1999, p. 594)

Incluso se afirma que "como las fronteras que definen los derechos son imprecisas, los conflictos devienen inevitables y problemáticos" (García-Pablos, 1985, p. 205).

De igual manera Isique (2012, citando a Castillo, 2005, p. 1) señala que:

... según las posturas conflictivistas de los derechos fundamentales, estos constituyen realidades jurídicas que de modo natural tienden a colisionar, siendo inevitables los conflictos, por lo que en esos casos la solución consiste en preferir un derecho y desplazar otro, es decir, se termina por colocar a uno de los derechos en conflicto por encima del otro.

\section{Controversia fundamental}

Una razón central de la controversia entre derechos se vincula estrechamente con el concepto de dignidad humana a la que refiere la Declaración Universal de Derechos Humanos, que en su Artículo № 1 señala: "Todos los seres humanos nacen libres e iguales en dignidad y derechos y, dotados como están de razón y conciencia, deben comportarse fraternalmente los unos con los otros" (Naciones Unidas, 1948, párr. 1).

Al respecto, el investigador oriental Lee (2008, citado por Bohórquez y Aguirre, 2009, p. 42) señala que:

A pesar de su status preeminente en el Derecho Internacional y en una gran cantidad de Constituciones Políticas, la dignidad no posee aún un significado concreto o una definición consistente. Esta falta de precisión suele llevar a que los jueces pongan sus propios estándares morales en medio de demandas opuestas de derechos que tienen posibilidades de ser consideradas como violaciones a la dignidad. La ambigua naturaleza de la dignidad humana se vuelve aún más problemática cuando se considera de forma intercultural. 
doi: http://dx.doi.org/10.15359/ree.19-3.2

URL: http://www.una.ac.cr/educare

CORREO: educare@una.cr

En consecuencia, la primera noción está cruzada por tres tensiones estrechamente relacionadas:

\section{- carácter natural / carácter consensual}

La tensión se encuentra entre la concepción natural de la dignidad humana frente a su carácter consensual.

Se plantea que:

... la dignidad es una característica "natural" con la que nacen todos los seres humanos. ... De esta manera, la dignidad aparece como el elemento definitorio de la idea de naturaleza humana... Desde esta perspectiva, es la naturaleza misma, o Dios, quien otorga a todo individuo perteneciente a la especie humana este atributo esencial Ilamado "dignidad". (Soulen, Woodhead, 2006, p. 8, citado en Bohórquez y Aguirre, 2009, p. 43)

De ser así, “... al Estado tampoco le quedaría otra opción diferente a reconocerle su dignidad, pues no son ellos quienes la otorgan" (Bohórquez y Aguirre, 2009, p. 43).

Sin embargo, frente a esta concepción, ya durante la elaboración de la carta fundamental de los derechos humanos, se postuló:

... la idea de dignidad humana es una característica artificial atribuida de forma consensual a todos los seres humanos, dada su utilidad, pero que, no obstante, no posee ninguna correspondencia con una alegada realidad de la naturaleza humana por cuanto la existencia de esta última es puesta en duda. De esta manera, no es cierto que los seres humanos nazcan con dignidad, como si se tratara de un atributo natural o esencial; ésta, más bien, es una ficción moral, política y, especialmente, jurídica que se predica de todos los miembros de la especie humana. Así, son los Estados, en particular los constitucionales respetuosos de los derechos y libertades, los que crean el principio jurídico-político de la dignidad humana. Esta creación se hace, en gran medida, como una manera de intentar garantizar la paz y la convivencia humana pacífica. (Hoerster, 1992, citado en Bohórquez y Aguirre, 2009, p. 44)

\section{- carácter abstracto / carácter concreto}

La tensión que opone el carácter abstracto frente a su carácter concreto, surge debido a que:

... la dignidad humana ha sido concebida como un imperativo general según el cual cada ser humano es un fin en sí mismo que, por ende, no puede ser instrumentalizado para 
doi: http://dx.doi.org/10.15359/ree.19-3.2

URL: http://www.una.ac.cr/educare

CORREO: educare@una.cr

ningún otro fin. Esto se traduce en una máxima moral según la cual cada ser humano racional debe tratarse a sí y a todos los seres humanos que comparten tal 'atributo' como un fin en sí mismo y nunca como un medio....

Sin embargo, este carácter de verdad incuestionable puede explicarse por el hecho de tratarse de una definición completamente vacía. En otras palabras, la idea abstracta de dignidad corre el riesgo de carecer de contenido práctico. Es por esto que los desacuerdos empiezan a aparecer cuando tal idea se va traduciendo en aspectos más concretos de la vida social y política, como por ejemplo, tener cierta clase de derechos y posibilidades (ciertos trabajos, cierto nivel educativo, ciertas relaciones sociales, etc.).

Es así como, además de aceptar alguna noción abstracta de lo que es la dignidad humana, el polo opuesto de esta segunda tensión enfatiza la necesidad según la cual la dignidad requiere de aspectos más concretos que tengan un mayor nivel de verificación. Entre estos aspectos se encontrarían, entre otros, la libertad de escoger una profesión pero también la garantía de recibir una remuneración justa por ella; la posibilidad de acceder a la educación pero también la libertad de escoger el tipo de la misma; el goce de ciertos derechos fundamentales y definitorios de lo que es un ser humano, como por ejemplo la propiedad privada, pero también el disfrute de los medios materiales indispensables para una vida valiosa, etc. (Peces-Barba, 2003, p. 77, citado en Bohórquez y Aguirre, 2009, pp. 44-45)

\section{- carácter universal / carácter particular}

La tensión se presenta entre:

... la existencia de un valor absoluto y universal como lo sería la dignidad humana el cual debería predicarse de todo ser humano en todo tiempo y lugar. En este sentido, la dignidad humana seria una sola, aplicable a todo individuo de la especie humana. (Pico Della Mirandola, 1984, p. 50, citado en Bohórquez y Aguirre, 2009, p. 45)

Sin embargo, dado que:

... la dignidad se relaciona con la idea de un buen vivir, resulta poco verosímil afirmar que... puede darse de forma absolutamente universal. Por el contrario, parece ser de mayor aceptación la idea según la cual cada cultura ha desarrollado, en diferentes tiempos y lugares, una idea del "vivir bien" y, en ese sentido, una idea de la dignidad. (Bohórquez y Aguirre, 2009, p. 46) 
doi: http://dx.doi.org/10.15359/ree.19-3.2

URL: http://www.una.ac.cr/educare

CORREO: educare@una.cr

Entonces, se evidencia que:

... el carácter particular de la dignidad, se refiere al hecho de que más que una "dignidad humana", lo que realmente existe es una multiplicidad de ideas de varias dignidades, cada una predicada en concreto de grupos sociales cultural e históricamente determinados. (Bohórquez y Aguirre, 2009, p. 46)

\section{Derechos en conflicto}

Además de las tensiones analizadas, diversas e innumerables son las situaciones donde los derechos entran en disputas. Piénsese en los conflictos que surgen en los derechos relacionados con la libertad y la igualdad, los intereses públicos y privados, el bien común y el bien individual, la libertad y el orden, la justicia y la inequidad, la libre expresión y las limitaciones a esta, el desarrollo económico y el desarrollo sustentable, las normativas legales nacionales y las normativas internacionales, entre la universalidad de los derechos humanos y el derecho a preservar las tradiciones culturales.

Por ejemplo, se presentan conflictos cuando:

- El derecho a la libre expresión y el derecho a la privacidad y la intimidada, se tensiona cuando un medio de comunicación da a conocer públicamente la vida íntima de una familia sin consentimiento de esta.

- El derecho al desarrollo económico que forman parte de los derechos económicos, sociales y culturales (Naciones Unidas. Derechos Humanos, 1966) y los derechos ambientales se tensionan cuando los países, en la búsqueda del desarrollo económico nacional, implementan modelos económicos que vulneran los derechos ambientales.

- El derecho a la vida y el derecho a la libertad personal entran en conflicto cuando el médico accede al pedido explícito de un paciente de interrumpir su vida para ejercer su derecho de libertad de elección voluntaria para interrumpir su vida por razones humanitarias (eutanasia).

- El derecho a la vida y el derecho al aborto terapéutico se tensionan porque la mujer tiene derecho a informarse y a tomar sus propias decisiones, las que no solo afectan su cuerpo sino su proyecto de vida. Por ello, la mujer tiene el derecho legítimo a tomar la decisión de continuar o interrumpir un embarazo, por ejemplo, cuando su embarazo es producto de una violación y el Estado la obliga a tener un hijo bajo esas circunstancias.

- El derecho que tiene la mujer al trabajo y el derecho a la igualdad y a una remuneración equitativa se tensiona porque, en muchos de los países de América Latina, las mujeres en trabajos que exigen las mismas calificaciones, competencias y desempeños perciben menos salarios que los hombres (un 30\% menos). 
doi: http://dx.doi.org/10.15359/ree.19-3.2

URL: http://www.una.ac.cr/educare

CORREO: educare@una.cr

- El derecho a la educación y el derecho a la libertad religiosa entran en disputa cuando el derecho consagrado en una serie de instrumentos internacionales y constitucionales a cursar la educación obligatoria en la escuela pública que, por definición, es laica, se prohíbe a una niña musulmana que asista a sus clases en un colegio público portando el hiyab o pañuelo símbolo de la religión musulmana, como ha sucedido en Francia.

- El derecho a no ser sometido a torturas ni a penas o tratos crueles, inhumanos o degradantes entra en conflicto con el derecho a la seguridad personal y colectiva, puesto que, en ocasiones, se aduce que hay necesidad de recurrir a métodos indignos e ignominiosos con el fin de que una persona entregue información respecto a un atentado que permitirá salvar la vida de mucha gente.

\section{Enseñanza de los derechos humanos centrada en el conflicto}

Dada la necesidad de reconocer los conflictos que existen entre los derechos y en su aplicación, se hace necesario incorporar el conflicto en la educación en derechos humanos. Por ello, se requiere de una estrategia pedagógica que se funde en los siguientes principios y una estrategia didáctica acorde con ella.

Los principios pedagógicos que orientan la enseñanza de los 'temas controversiales' en derechos humanos se vinculan estrechamente con la pedagogía crítica, la que se sustenta en la teoría critica de la Escuela de Frankfurt (Horkheimer, 2000). La pedagogía crítica vincula a la pedagogía crítica con una práctica moral y política. Por ello, descarta la idea de que la pedagogía sea un problema de método, un problema práctico y técnico. La pedagogía crítica es un enfoque educativo que intenta deliberadamente influenciar en cómo y qué conocimiento e identidades se producen en cada relación de poder y contexto particular.

Paulo Freire, quien es considerado el inspirador de la pedagogía critica, desarrolló su propuesta de alfabetización conforme con su filosofía concientizadora, apelando al debate grupal sobre situaciones existenciales significativas para quienes se incorporaban al mundo de la lecto-escritura, en las que el sujeto debía ser activo, dialogante y desarrollar su espíritu crítico. Este método psicosocial, basado en el concepto antropológico de cultura y en la distinción entre el mundo de la naturaleza y el de la cultura, es de carácter inductivo, porque parte de la realidad existencial inmediata de los sujetos, aunque la trasciende y amplía; es dialógico, porque se desarrolla con base en la discusión colectiva; y es problematizador de la realidad que circunda al sujeto (Freire, 1985, 2009).

Por tanto, si desde esta perspectiva, lo central son el sujeto docente y el sujeto estudiante, en tanto sujetos de derechos, que se construyen en la interacción y el diálogo intersubjetivo, la enseñanza de los 'temas controversiales' en educación en derechos humanos requiere tener en cuenta que: 
doi: http://dx.doi.org/10.15359/ree.19-3.2

URL: http://www.una.ac.cr/educare

CORREO: educare@una.cr

El poder simbólico se distribuya equitativamente, de suerte que cada participante de la situación educativa tenga la posibilidad y capacidad de expresarse y decidir libremente y ser escuchado o escuchada en relación con el 'tema controversial' sobre los derechos humanos analizado. De esta manera, el proceso dialógico se convierte en una herramienta de aprendizaje y de empoderamiento.

El diálogo intersubjetivo se debe estructurar de acuerdo con las reglas y el marco referencial que establece el mismo grupo dialogante, para asegurarse que la totalidad participe y exprese sus interpretaciones sobre el tópico en cuestión.

Al comenzar el análisis de un 'tema controversial' en derechos humanos, y después de una motivación y explicación sucinta por la parte docente, se debe dar cabida a que el estudiantado se pronuncie respecto al tópico desde sus pre-concepciones, considerando sus historias personales y su vida cotidiana. Luego, se requiere un espacio para que el personal docente incorporare información relevante proveniente de diferentes fuentes informadas y rigurosas a las que va a recurrir el estudiantado para, nuevamente, examinar el 'tema controversial' desde diversos puntos de vista.

El tratamiento de los 'temas controversiales' en la educación en derechos humanos en interacción dialógica, es un proceso que tiene como propósito fundamental apoyar la construcción del sujeto de derechos, pero también es un espacio que permitequeel conocimiento emerja como resultado de la aproximación de los saberes construidos en la vida cotidiana de estudiantes y de los saberes que circulan en los contextos donde su vida tiene lugar.

Al presentarle al estudiantado situaciones controversiales sobre derechos humanos, se intenta desarrollar competencias cognitivas, afectivas y sociales necesarias para que participe de una sociedad democrática como sujeto crítico y defensor de los derechos humanos. Específicamente, permite desarrollar habilidad para reconocer diferentes puntos de vista, desarrollar el razonamiento crítico y la evaluación basada en la evidencia en el análisis de temas significativos. Esto, porque el análisis de 'temas controversiales', en general y los relacionados con los derechos humanos, en especial, capacita al estudiantado para analizar críticamente problemas sociales relevantes en que los derechos humanos están en juego.

Una pedagogía centrada en el conflicto considera la libertad de elegir, de expresarse, de tomar decisiones; condiciones necesarias del espacio pedagógico donde se forma al sujeto de derechos. Solo en esas condiciones, cuando el estudiantado elija qué y cómo abordar un 'tema controversial', tendrá más posibilidades de desarrollar perspectivas críticas.

El tratamiento de los 'temas controversiales' referidos a los derechos humanos en la deliberación y el diálogo tiene como propósito fundamental apoyar la construcción del sujeto de derechos. Es un espacio que permite que el conocimiento emerja como resultado de la aproximación de los saberes propios de la experiencia cotidiana del estudiantado y de los saberes acumulados en torno a los temas que se analizan. 
doi: http://dx.doi.org/10.15359/ree.19-3.2

URL: http://www.una.ac.cr/educare

CORREO: educare@una.cr

La estrategia didáctica propia de la educación en derechos humanos centrada en el conflicto, al fundarse en la deliberación y el diálogo, debe asegurar que el poder se distribuya equitativamente, de suerte que cada participante de la situación educativa tenga la posibilidad de expresarse, de decidir libremente y de ser escuchado. Esto no significa que se trate de un encuentro carente de planificación. Por el contrario, como toda acción pedagógica, esta debe estar debidamente planificada con el propósito de obtener los resultados esperados. Pero, en la planificación y organización de la situación de aprendizaje, participan tanto el personal docente como el estudiantado, estableciendo conjuntamente la reglas, por ejemplo: escuchar con respeto, no interrumpir, respetar las opiniones expresadas por otras personas, criticar las ideas no a las personas, permitir a los otros individuos la oportunidad de expresarse, etc. Así, la deliberación y el dialógico se convierten en una herramienta de aprendizaje y de empoderamiento.

La estrategia pedagógica-didáctico focalizada en la deliberación y el diálogo demanda al profesoradocrearcondicionesquelespermitanasusestudiantesexpresarlibrementesuscontradicciones y ambigüedades sobre el tópico analizado. También, le pide cuestionar las preconcepciones propias y ajenas, explorar pensamientos y sentimientos, escuchar sin juzgar -con el propósito de entender y validar las experiencias y sentimientos de las otras personas-, buscar significados compartidos y diversificar sus interpretaciones, trabajar en equipo, articular áreas de conflicto y diferencias, construir relaciones y tomar decisiones (Zuñiga, Nagda, Chesler y Cytron-Walker, 2007).

Además, el profesorado debe estar capacitado para enfrentar posibles dificultades y resistencias que se presentan en las instituciones educacionales, su personal directivo y padres y madres de familia cuando se enseñan 'temas controversiales'. En efecto, la bibliografía evidencia que en muchas ocasiones el profesorado es reticente a enseñar 'temas controversiales' por temor a que se le acuse de ser parcial o de ocultar segundas intenciones, estar implicado en las argumentaciones que expone y en el debate (Cotton 2006), temor a que los 'temas controversiales' puedan conducir a que se desarrollen animosidad entre el propio estudiantado (Wilson, Hass, Laughlin y Sunal, 2002).

Sin embargo, es fundamental que los'temas controversiales' presentes en la educación en derechos humanos se trabajen en la escuela, porque en esas instancias el estudiantado puede hacer uso de su libertad de elección y de expresión, y puede tomar decisiones al interior de la escuela (Magendzo, 2006). Puede vivenciar una genuina y auténtica experiencia de vida en democracia y formarse como ciudadanos y ciudadanas de una sociedad diversa y tensionada por múltiples conflictos. Prueba de ello es que, quienes analizan 'temas controversiales', durante su trayectoria escolar, desarrollan interés por lo político (Hahn, Angell y Tocci, 1988), reportan una actitud política más positiva, mayor participación en actividades políticas (Harwood y Hahn, 1990), mayor tolerancia cívica (Goldenson, 1978) e interés en los temas sociales (Curtis y Shaver, 1980). Por eso, algunas escuelas han incorporado los'temas controversiales' en el currículo como una estrategia para promover la futura participación política de sus estudiantes (Hess, 2005). 
doi: http://dx.doi.org/10.15359/ree.19-3.2

URL: http://www.una.ac.cr/educare

CORREO: educare@una.cr

\section{Referencias}

Apple, M. (1986). Ideología y currículo. Madrid: Ediciones Akal.

Asimeng-Boahene, L. (2007). Creating Strategies to Deal with Problems of Teaching Controversial Issues in Social Studies in African Schools [Creando estrategias para lidiar con problemas de enseñar temas controversiales en Estudios Sociales en escuelas africanas]. Intercultural Education, 18(3), 231-242. doi: http://dx.doi.org/10.1080/14675980701463588

Bohórquez, V. y Aguirre, J. (Diciembre, 2009). Las tensiones de la dignidad humana: Conceptualización y aplicación en el derecho internacional de los derechos humanos. Sur Revista Internacional de Derechos Humanos, 6(11), 41-63. Recuperado de http://www. surjournal.org/esp/conteudos/pdf/11/02.pdf

Castillo, L. F. (Enero-Junio, 2005). ¿Existen los llamados conflictos entre derechos fundamentales? Cuestiones Constitucionales, 12, 99-129. Recuperado de http://www.redalyc.org/articulo. oa? id=88501204

Cotton, D. R. E. (2006). Teaching Controversial Enviromental Issues. Neutrality and Balance in the Reality of the Classroom [Neutralidad y Equilibrio en el contexto del aula]. Educational Research, 48(2), 223-241. Recuperado de http://scholar.google.com/ scholar url?hl=es\&q=http://www.researchgate.net/publication/228785938 Teaching controversial environmental issues neutrality and balance in the reality of the classroom/file/e0b49519295bf20899.pdf\&sa=X\&scisig=AAGBfm2QnDUXFY Cdcesjs ss gx9bHTjw\&oi=scholarr

Crick, B. (1998). Education for Citizenship and the Teaching of Democracy in Schools (Final report of the Advisory Group on Citizenship) [Educación parciudadanía yla enseñanza de la Democracia en escuelas (Reporte final del grupo asesor en ciudadanía]. Great Brfitain: Cualificaciones y Curriculum Authority. Recuperado de http://dera.ioe.ac.uk/4385/1/crickreport1998.pdf

Curtis, C. y Shaver, J. P. (Abril, 1980). Slow Learners and the Study of Contemporary Problems [Estudiantes con ritmo de aprendizaje lento y el estudio de problemas contemporáneos]. Social Education, 44(4), 302-309.

Freire, P. (1985). Pedagogía del oprimido. Buenos Aires: Siglo XXI Editores.

Freire, P. (2009). La educación como práctica de la libertad. Madrid: Siglo XXI de España Editores.

Goldenson, D. R. (1978). An Alternative View About the Role of the Secondary School in Political Socialization: A Field-Experimental Study of the Development of Civil Liberties Attitudes [Una mirada alternativa respecto al rol de la enseñanza secundaria en la socialización política: Un estudio piloto en el desarrollo de las actitudes vinculadas a las libertades civiles]. Theory \& Research in Social Education, 6(1), 44-72. doi: http://dx.doi.org/10.1080/0 0933104.1978.10506023 
doi: http://dx.doi.org/10.15359/ree.19-3.2

URL: http://www.una.ac.cr/educare

CORREO: educare@una.cr

Hahn, C., Angell, A. y Tocci, C. (Junio, 1988). Civic Attitudes in Five Nations [Actitudes Cívicas en cinco países I]. Ponencia presentada en International Meating of the Social Studies. Columbia, Canada.

Hardwood, A. y Hahn, C. (1990). Controversial Issues in the Classroom [Temas controversiales en el aula]. Recuperado de http://www.ericdigests.org/pre-9218/issues.htm

Hess, D. (Enero-Febrero, 2005). How do Teachers' Political Views Influence Teaching About Controversial Issues? [¿De qué manera la postura política del maestro influye en la enseñanza de temas controversiales?]. Social Education, 69(1), 47-48. Recuperado de http://www.procon.org/sourcefiles/Views.pdf

Horkheimer, M. (2000). Teoría tradicional y teoría crítica. Barcelona: Paidós.

Isique, M. D. (2012). Los conflictos entre derechos fundamentales y los métodos de resolución. Recuperado de http://www.ussvirtual.edu.pe/Documentos/ derecho/produccionjuridica/200902/LOS CONFLICTOS ENTRE DERECHOS FUNDAMENTALES Y LOS METODOS DE RESOLUCION.dOC

Levinson, R. (Agosto, 2006). Towards a Theoretical Framework for Teaching Socio-Scientific Controversial Issues [Acercamiento a un marco teórico para enseñar temas sociocientíficos controversiales]. International Journal of Science Education, 28(10), p. 1201-1204. doi: http://dx.doi.org/10.1080/09500690600560753

Magendzo, A. y Donoso, P. (1992). Diseño curricular problematizador en la enseñanza de los derechos humanos. Cuadernos de educación en y para los derechos humanos IIDH-PIIE, 4.

Magendzo, A. (2000). Dilemas y tensiones en torno a la educación en derechos humanos en democracia. Recuperado de http://biblio.juridicas.unam.mx/libros/4/1840/34.pdf

Magendzo, A. (2006). Educación en derechos humanos: Un desafío para los docentes de hoy. Santiago: Lom Ediciones.

Magendzo, A. (Ed.). (2009). Pensamiento e ideas fuerza en la educación en derechos humanos en Iberoamérica. Santiago: UNESCO / OIE / Editorial SM. Recuperado de http://unescopaz. uprrp.edu/documentos/ideasfuerza.pdf

Naciones Unidas. (1948). Declaración Universal de Derechos Humanos. Recuperado de http:// www.un.org/es/documents/udhr/

Naciones Unidas Derechos Humanos. (1966). Pacto Internacional de Derechos Económicos, Sociales y Culturales. Recuperado de www.ohchr.org/SP/Professionallnterest/Pages/ CESCR.aspx 
doi: http://dx.doi.org/10.15359/ree.19-3.2

URL: http://www.una.ac.cr/educare

CORREO: educare@una.cr

Oultdon, C., Day, V., Dillon, J. y Grace, M. (2004). Controversial Issues - Teachers' Attitudes and Practices in the Context of Citizenship Education [Temas controversiales: La actitud y la práctica del docente en el contexto de la educación civica]. Oxford Review of Education, 30(4), 489-507. doi: http://dx.doi.org/10.1080/0305498042000303973

Sacavino, S. B. (2012). Democracia y educación en derechos humanos en América Latina. Bogotá: Ediciones desde abajo.

Toledo, M. I., Magendzo, A., Gutiérrez, V. e Iglesias, R. (En prensa). Enseñanza de 'temas controversiales' en la asignatura de historia y ciencias sociales desde la perspectiva de los profesores. Revista Estudios Pedagógicos.

Toledo, M. I., Magendzo, A., Gutiérrez, V., Iglesias, R. y López-Facal, R. (En prensa). Enseñanza de 'temas controversiales' en el curso de historia, desde la perspectiva de los estudiantes chilenos. Revista de Estudios Sociales.

Wilson, E. K., Hass, M. E., Laughlin, M. A.y Sunal, C. S. (2002). Teacher's Perspective on Incorporating Current Controversial Issues into the Social Studies Curriculum [La perspectiva del docente al incorporar temas controversiales presentes en el currículum de las ciencias sociales]. International social studies forum, 2(1), 31-45.

Zuñiga, X., Nagda, B., Chesler, M. y Cytron-Walker, A. (2007). Intergroup Dialogue in Higher Education: Meaningful Learning About Social Justice [Diálogo intergrupal en la educación superior: Aprendizaje significativo respecto a la justicia social]. ASHE Higher Education Report, 32(4), 1-150.

\section{Cómo citar este artículo en APA:}

Magendzo-Kolstrein, A. y Toledo-Jofré, M. I. (Setiembre-Diciembre, 2015). Educación en derechos humanos: Estrategia pedagógica-didáctica centrada en la controversia. Revista Electrónica Educare, 19(3), 1-16. doi: http://dx.doi.org/10.15359/ree.19-3.2

Nota: Para citar este artículo en otros sistemas puede consultar el hipervínculo "Como citar el artículo" en la barra derecha de nuestro sitio web: http://www.revistas.una.ac.cr/index.php/EDUCARE/index 